\title{
Comparison of Healing Time Following Modified Radical Mastoidectomy with or without Mastoid Cavity Obliteration
}

\author{
Tulachan $\mathrm{B}^{1 *}$, Swar $\mathbf{R}^{1}$ and Borgohain BN \\ ${ }^{1}$ ENT Lecturer, Universal College of Medical Sciences, Nepal \\ ${ }^{2}$ ENT, Professor and HOD, Universal College of Medical Sciences, Nepal
}

Submission: May 09, 2018; Published: May 25, 2018

*Corresponding author: Bishow Tulachan, Lecturer, department of ENT-HNS, Universal College of Medical Sciences, Teaching Hospital, Bhairahawa, Lumbini, Nepal, Tel:-977-9849609446; Email: tulachanbishow@hotmail.com

Abstract

Modified radical mastoidectomy (MRM) is a type of canal wall down mastoidectomy usually reserved for chronic otitis media squamous active type of disease which is considered as an unsafe type due to high incidence of complications. The motives of doing mastoidectomy in such disease are creating a disease -free and dry ear, the prevention of recurrent disease, and the maintenance of hearing or the possibility to reconstruct an affected hearing mechanism. Canal wall down mastoidectomy has been used to achieve those goals with greater or lesser degrees of success on long term. However, canal wall down is an aggressive approach, as it involves creating an open cavity and changing the anatomy and physiology of the middle ear and mastoid. A canal wall up technique eliminates the need to destroy the middle ear and mastoid, but is associated with a higher rate of residual disease. Hence the cavity obliteration techniques arise as an effort to avoid the disadvantages of both techniques.

Purpose: to compare the healing time after MRM with or without mastoid obliteration in all age groups.

Materials and Methods: It was a prospective, longitudinal, comparative, interventional study done in Ear, Nose and Throat (ENT) department of Universal College of Medical Sciences (UCMS), teaching hospital, Bhairahawa, Nepal. Patients diagnosed with chronic otitis media squamous type in active stage of age $\geq 8$ years were included. A total of 30 patients underwent modified radical mastoidectomy (MRM) under general anesthesia in one year period. Study population was randomly divided into two groups: group A (n=15): MRM with mastoid cavity obliteration using inferiorly based musculofascioperiosteal flap and group B (n=15): MRM without mastoid cavity obliteration ( $\mathrm{n}=15)$. Healing time (weeks) and complications were recorded in both groups after surgery i.e. 10 - 14 days, 4-6 weeks, 12 weeks and compared.

Results: all the patients had healed cavities postoperatively. However, the average healing period in group A was 10.67 weeks and in group B 12.47 weeks. It was statistically significant in healing time between the two groups ( $p$ value $=0.005$ ).

Conclusion: The average healing time in MRM with mastoid cavity obliteration is a bit earlier (10.67 weeks) to MRM without mastoid cavity obliteration (12.47 weeks) with statistical significance.

Keywords: Chronic otitis media; Modified radical mastoidectomy; Mastoid cavity obliteration; Healing

Abbreviations: MRM: Modified Radical Mastoidectomy; UCMS: Universal College Of Medical Sciences; ENT: Ear Nose and Throat; COM: Chronic Otitis Media; WHO: world health organization; ETD: Eustachian tube dysfunction; TNF: Tumor Necrosis Factor; CAT: Combined Approach Tympanoplasty; CWD: canal wall down; CWU: Canal Wall Up; SPSS: statistical package for social sciences; PTA: Pure Tone Audiogram; OPD: Out Patient Department

\section{Introduction}

Chronic otitis media (COM) is a common entity frequently seen by an Otolaryngologist in their day to day practice [1]. It is characterized as a permanent abnormality of the pars tense or flaccida, most likely a result of earlier acute otitis media, negative middle ear pressure or otitis media with effusion. COM squamous active is a type of COM, which is associated with production of pus, retraction of pars flaccida or tense with retained squamous epithelial debris [2]. COM is still one of the most common ear diseases with the chief complaints being persistent ear discharge and hearing loss in many of the developing countries and the prevalence of squamous type of COM is $3.5 \%$ in Nepal $[1,4]$. The World Health Organization (WHO) estimates that over $5 \%$ of the world's population -360 million people -has disabling hearing loss (328 million adults and 32 million children) [5]. Several factors like genetic, infections, allergy, and environmental, social and racial factors are considered as the etiology and pathogenesis of otitis media [6]. COM results from long - term 
Eustachian tube dysfunction (ETD) with a poorly aerated middle -ear space, multiple episodes of acute otitis media (AOM), persistent middle -ear infection, or other chronic inflammatory stimulus. The prevalence of COM in developing countries are mainly consequent to poor hygiene, overcrowding, nutritional deficit \& poor living condition [7]. There's a dramatic decline in the incidence of COM nowadays secondary to improvements in housing, hygiene and antimicrobial therapy. However, ignorance, poverty and traditional beliefs are the principal risk factors for not attending hospital in rural parts of Nepal [8].

COM is an important cause of preventable hearing loss, particularly in the developing world, and a reason of serious concern, particularly in children, because it may have long term effects on early communication, language development, auditory processing psychosocial and cognitive development, and educational progress and achievement [9]. COM squamosal active type has numbers of etiologic factors; Poor Eustachian function and reduced middle ear cleft volume has been shown to be characteristic of ears with cholesteatoma \& infection, inflammation, pressure and keratin can lead to elaboration of a variety of molecular factors including cytokines such as interleukins (IL -1, IL -6), tumor necrosis factor (TNF), other protein mediators such as growth factors, and non - protein mediators such as prostaglandins, neurotransmitters and nitric oxide lead to the activation of osteoclasts that results in bone resorption \& cause erosion of adjacent bone and ossicles leading to conductive hearing impairment [1], persistent foul smelling ear discharge and hearing impairment are the main complaints that patients are concerned with in such cases. The role of medical treatment is very limited so patients are advised to undergo surgical intervention as soon as possible due to higher chances of complications. Preoperatively patients are counseled about the goals of surgery. The goal of surgery is to make ear dry and safe by eradicating the disease and reconstruction of hearing mechanism as much as possible.

In early days, the radical surgery was mainly aimed at disease eradication without giving attention to hearing restoration. Now the emphasis is also on control of the disease with preservation and reconstruction of the hearing mechanism. In 1960s, conservative canal wall up procedures like combined approach tympanoplasty (CAT) described by Jansen were very popular. However, now the emphasis is back on canal wall down (CWD) procedures for better eradication of cholesteatoma and hearing restoration. The goals of surgery are to eliminate epithelial and bone disease thoroughly and prevent recurrent disease, to produce a dry and safe ear and to restore serviceable hearing [10]. The most effective surgical method for treating middle ear cleft cholesteatoma and COM has been debated for decades, especially with regard to differences in efficacy between CWD and canal wall up (CWU) mastoidectomy [11]. The surgery is done either in one stage or multiple stages with reconstruction of canal wall later $[12,13]$. CWD mastoidectomy or open cavity mastoidectomy includes all surgeries where the posterior canal wall is lowered partially or totally. Among CWD surgeries Modified Radical Mastoidectomy (MRM) is the most commonly performed for active COM squamosal type disease mainly in developing countries, offering a mastoid cavity for the entire life [14]. CWD mastoidectomy is one of those common surgical techniques with variations of long -term outcomes. Although the majority of patients experience little to no longterm problems postoperatively, there is a small but expressive number of patients with chronic complaints associated with the persistent mastoid cavity [15].

Recurrent drainage and infection are the most common cause of discontent and medical return for patients with mastoid cavities. Other frequent complaints may include water intolerance, leading to infection, the need for frequent otomicroscopic cleaning, calorically induced vertigo from either water or air exposure, barometrically induced vertigo, and, in those with compromising hearing loss, being unable to wear traditional hearing aids due to wide meatoplasty [16]. The open cavity problems can be avoided by obliterating the mastoid cavity in a same sitting while performing canal down technique or can be done later in the second sitting [14]. Mosher, in 1911, started the idea of mastoid obliteration to promote healing of a mastoidectomy defect. Mosher described an obliteration technique using a superiorly based post auricular soft tissue flap [17]. The researcher noticed that the muscle atrophied over time, causing a progressive enlargement in cavity size. This observation is supported by histological data from the temporal bone study of Linthicum [18] which demonstrates the replacement of muscle with fibro-connective tissue and fat. These findings [8] encouraged surgeons to associate other filler materials inside the cavity. Palva [19] modified and popularized the technique, further adding to it the use of bone chips and bone pate in combination with an anteriorly based musculoperiosteal flap [19]. Over the course of the last decades, there have been a large number of reports detailing a multiplicity of techniques for obliterating the mastoid cavity.

The most frequent and popular techniques consist of either local flaps (muscle, periosteum, or fascia) or free antilogous grafts (bone, cartilage, fat, fascia), or even alloplastic grafts (hydroxyapatite, silicon, synthetics bones, among others) [15]. By obliterating the mastoid cavity, the cavity lining derives the nutrition and vascularity which is considered to be faded off after the surgery as the neo cavity is smoothened with the polishing burr and also the epithelial regeneration is compromised. Consequently, post obliteration of the cavity, the size of the mastoid cavity is reduced and the lining process is hastened if the pedicled graft is used. The problem with the obliteration technique is of difficulty in seeing the recurrence of disease in the mastoid cavity [20]. In developing countries like Nepal most of the patient are from rural area and lack regular follow up for cleansing mastoid cavity due to long distance, economic burden \& lack of transportation. Thus patient can avail with mastoid cavity obliteration resolving the cavity problems. 


\section{Global Journal of Otolaryngology}

In our study we have used healthy mastoid cortex bone chips, bone dust and the inferiorly based musculofascioperiosteal flap for mastoid obliteration in all the age groups. Accordingly this study was conducted to compare the healing time in obliterated and non- obliterated mastoid cavities in COM-squamous active type disease.

\section{Materials and Methods}

A prospective, longitudinal, comparative and interventional study was conducted from August 2015 to July 2016 at Department of ENT and Head and Neck Surgery, Universal College of Medical Sciences, Teaching Hospital, Bhairahawa, Lumbini Zone, Nepal. The study population comprised patients of age $\geq 8$ years, all genders with COM squamous active (cholesteatoma) disease. Study population was randomly divided into two groups consisting of 15 patients in each group as Group A (MRM with mastoid cavity obliteration) and Group B (MRM without mastoid cavity obliteration). The study excluded children of age $<8$ years with complications of chronic otitis media, revision MRM and with histologically proven middle ear diseases other than COM squamous e.g., tuberculosis. Statistical Package for Social Sciences (SPSS) 23.0 software was used for data analysis and independent $\mathrm{T}$ test was applied. The level of significance was set at $\mathrm{p}<0.05$. Informed consent was taken from all patients preoperatively after explaining the procedure. Ethical approval was taken from Institutional Review Committee Universal College of Medical Sciences. Patient with com squamosal active disease who were diagnosed in OPD by residents and consulted with faculties were send for PTA (pure tone audiogram), routine investigations, x-ray mastoid lateral oblique view \& Towne's view and posted for routine MRM under GA. All the cases were done by the faculties.

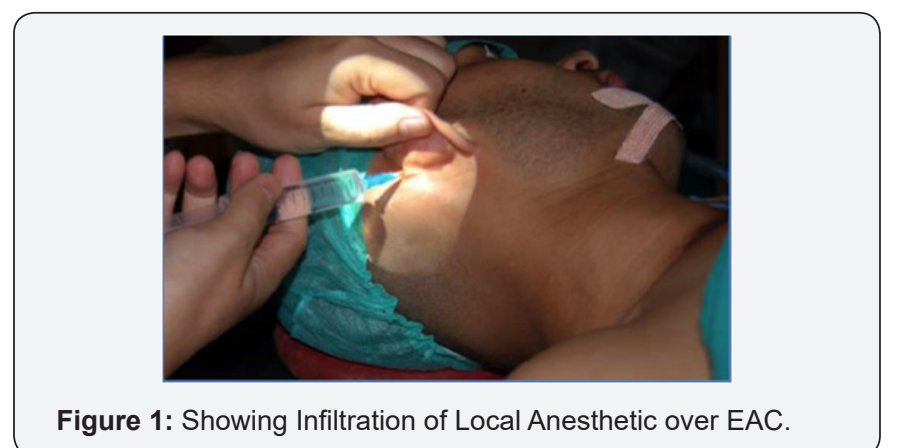

Patients were admitted one day prior to surgery in ENT ward. Prophylactic antibiotic ceftriaxone of 1gram given intravenously 2-4 hour prior to surgery. On the day of surgery shaving was done approximately $2 \mathrm{~cm}$ superiorly from the upper attachment of pinna and $2 \mathrm{~cm}$ posteriorly from retroauricular groove in the ear to be operated. After the patient was anesthetized, the patient's head was turned to opposite side. Local anesthetic agent $2 \%$ lignocaine with adrenaline 1:200,000 solution approximately around $5 \mathrm{ml}$ was used for local infiltration into the incision site and the four quadrants of EAC for hemostasis (Figure 1). After induction of anesthesia, the pinna and the surrounding area was painted and draped. Examination under microscope (EUM) was performed and findings noted (Figure 2).

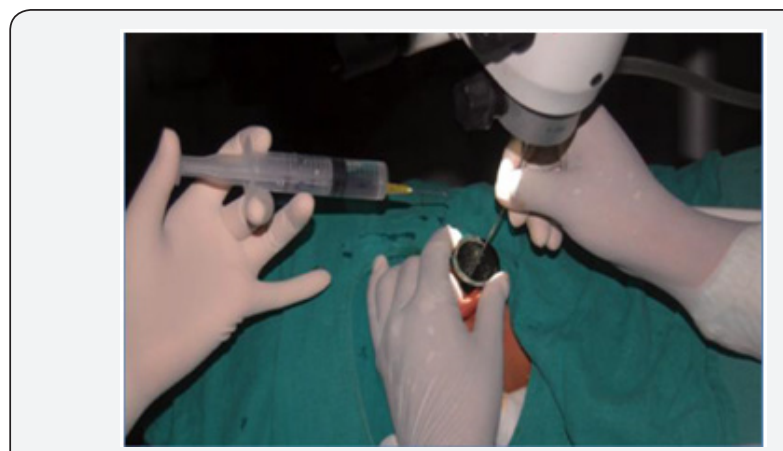

Figure 2: Irrigation \& Examination under Microscope.

\section{Surgical procedure}

The post aural approach was applied in both groups and the technique was either in to out or out to in. Patients in group $B$ underwent classical MRM whereas patients in group A had some modifications in the surgical steps as described later. A standard tympanomeatal flap was raised. A curved postaural incision was made $2 \mathrm{~cm}$ posterior and parallel to the post auricular groove extending from around $1 \mathrm{~cm}$ above the superior attachment of pinna to the mastoid tip so as to obtain a large generous flap (Figure 3). By exposing the temporalis fascia overlying the muscle, a large temporalis fascia graft was harvested from the upper part and the remaining fascia was kept intact inferiorly so as to have an adequate flap for obliteration (Figure 4). An inferiorly based musculofascioperiosteal flap with its base on the mastoid process with its length extending $1 \mathrm{~cm}$ superiorly to superior attachment of pinna was fashioned (Figure 5). The flap comprised of subcutaneous tissue and periosteum in lower part and temporalis fascia, muscle and periosteum in upper part and was about $3-4 \mathrm{~cm}$ in width (Figure 5). Temporalis muscle and fascia were exposed and a large temporalis fascia graft harvested from the upper part of the temporalis fascia keeping the remaining fascia intact in lower part to create a flap for obliteration (Figure 4). The flap was turned inferiorly and kept wrapped in wet gauze and kept wet by pouring normal saline on it time to time. Initially the normal mastoid cortical bone was collected using a gouge and hammer (Figure 6). Bone dust was collected while drilling normal bone from the healthy mastoid cortex (Figure 7). Then, CWD mastoidectomy was performed.

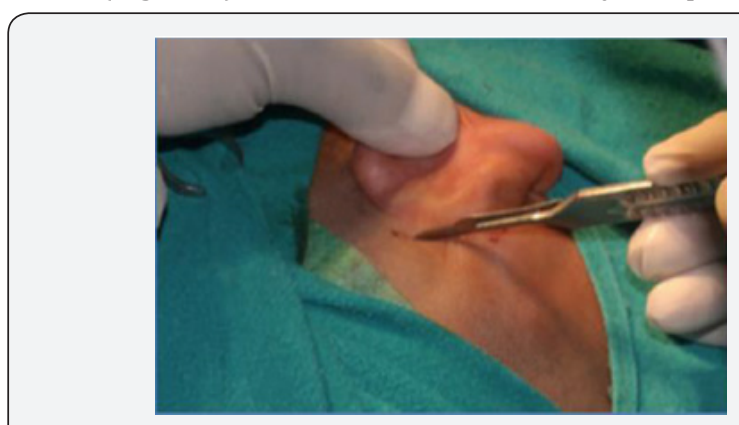

Figure 3(a): Postaural Incision. 


\section{Global Journal of Otolaryngology}

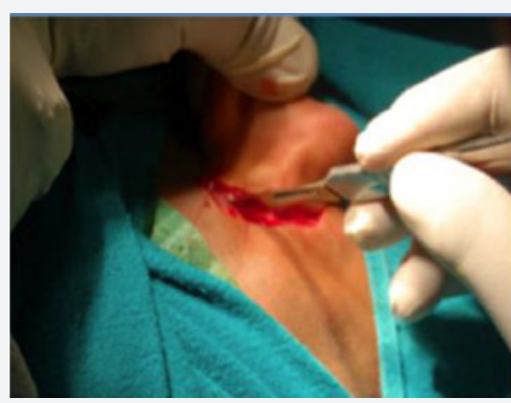

Figure 3(b): Postaural Incision

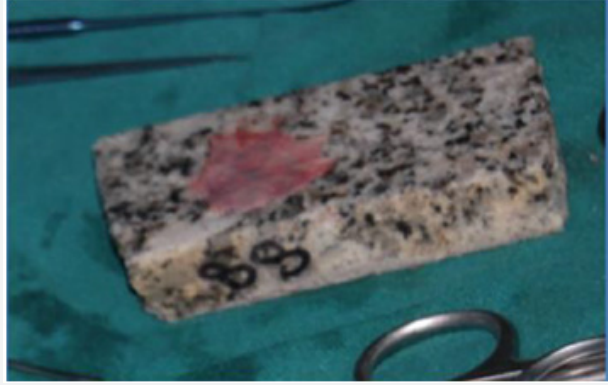

Figure 4: Harvested Temporalis Fascia.
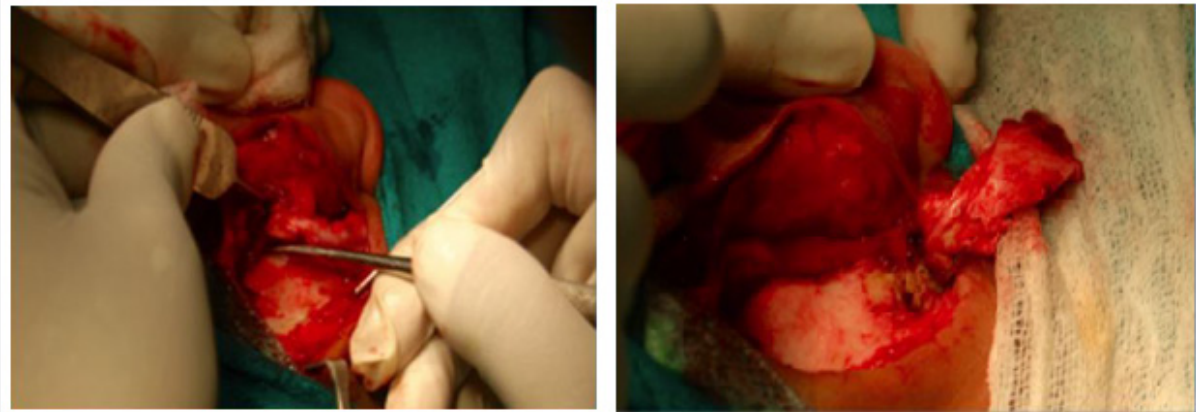

Figure 5: Inferiorly Based Musculofascio Periosteal Flap.

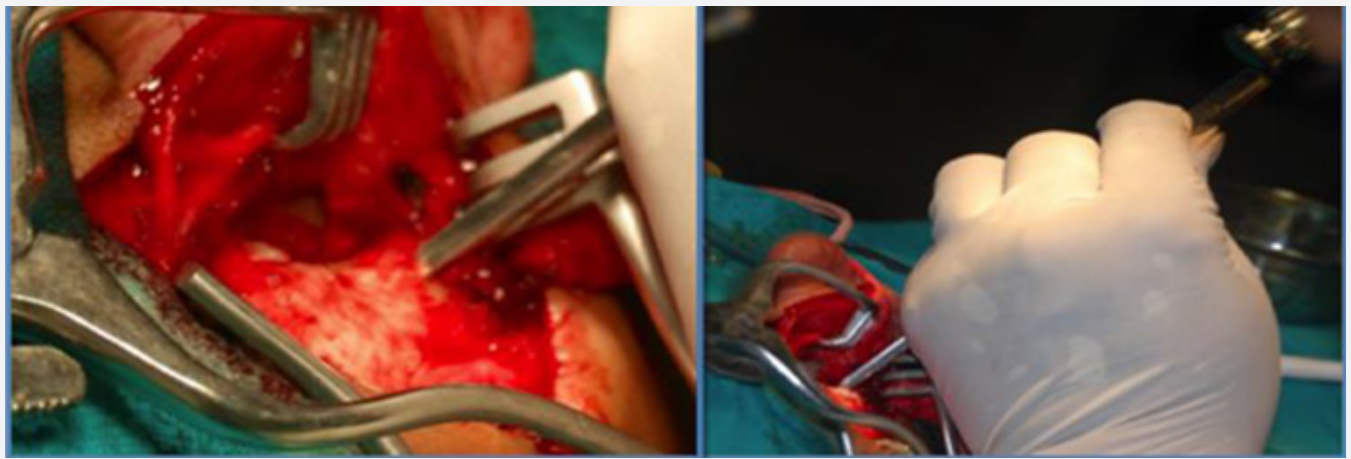

Figure 6: Normal Mastoid Coritical bone Collected Using a Gouge and Hammer.

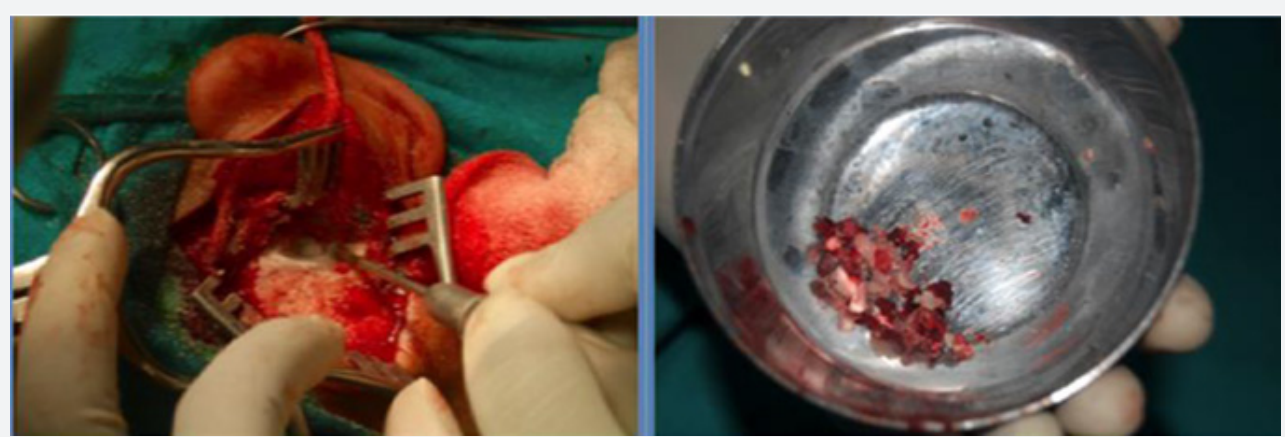

Figure 7: Collection of Mastoid Cortical bone Chips and Healthy bone Dust.

The posterior canal wall was lowered adequately to eradicate the disease process (Figure 8). To have better obliteration, the saucerization of the mastoid cavity was avoided. After the entire removal of disease from the middle ear cleft, the attic and the posterior canal wall were reconstructed by sculpturing the mastoid cortical bone which was taken previously and the rest of cavity and spaces were obliterated by putting pieces of cortical bones and bone dust (Figure 9). The inferiorly based 


\section{Global Journal of Otolaryngology}

muscle of a sci periosteal flap was placed over the bone chips and dust filled with cavity (Figure 10). The temporalis fascia was placed in middle ear as in the usual reconstruction as well as used to cover the attic reconstruction, posterior canal wall, and if possible obliterated mastoid cavity with bone chips, dust and flap. Gel foam pieces were kept in the middle ear and over external auditory canal (EAC) and the graft, and rest of the canal was packed with medicated pack. Routine wide meatoplasty was done in group B however meatoplasty was not fashioned in group a cases. The incision was closed in two layers (soft tissue with vicryl 3.0 round body and skin with proline 4.0 cutting body) (Figure 11). The mastoid bandage was applied the dressing was changed on the first postoperative day (POD) and on alternate days. Oral amoxicillin and clavulinic acid was prescribed for 2 weeks. Oral paracetamol - ibuprofen (10-15mg/ $\mathrm{kg}$ eight hourly) combined was prescribed for 3 days then if necessary for analgesia and oral antihistamines were also prescribed. Sutures and medicated pack were removed on the 7 th postoperative day (POD). Patient was discharged on the 7 th postoperative day (POD). Topical (antimicrobial and steroid) eardrop was prescribed for 4-6 weeks. All patients were advised for strict aural precautions post operatively. Post operatively patients were assessed on 10-14 days, 4-6 weeks and 12 weeks. The healing time of the mastoid cavity were recorded in both the groups. Dry ear was defined as lining of the external auditory canal and middle ear without signs of infection.

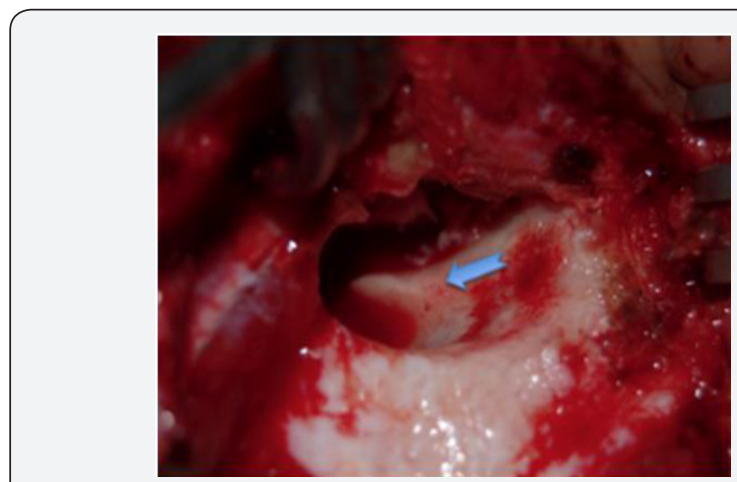

Figure 8: The Posterior Canal Wall Lowered.

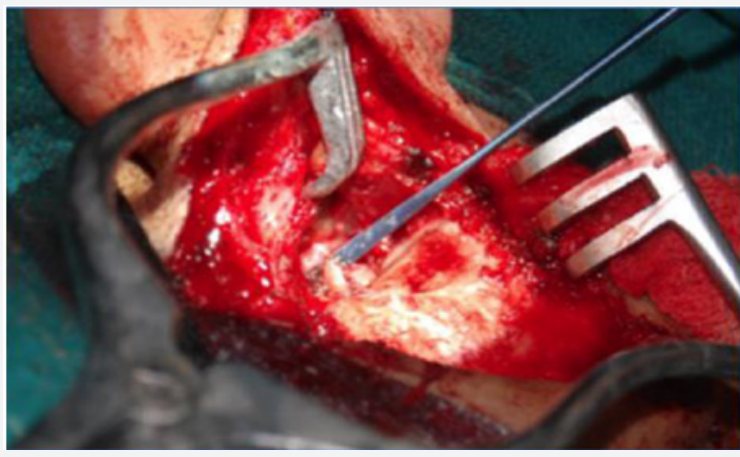

Figure 9: Mastoid Cavity Filled With Bone Chips and Bone Dust.
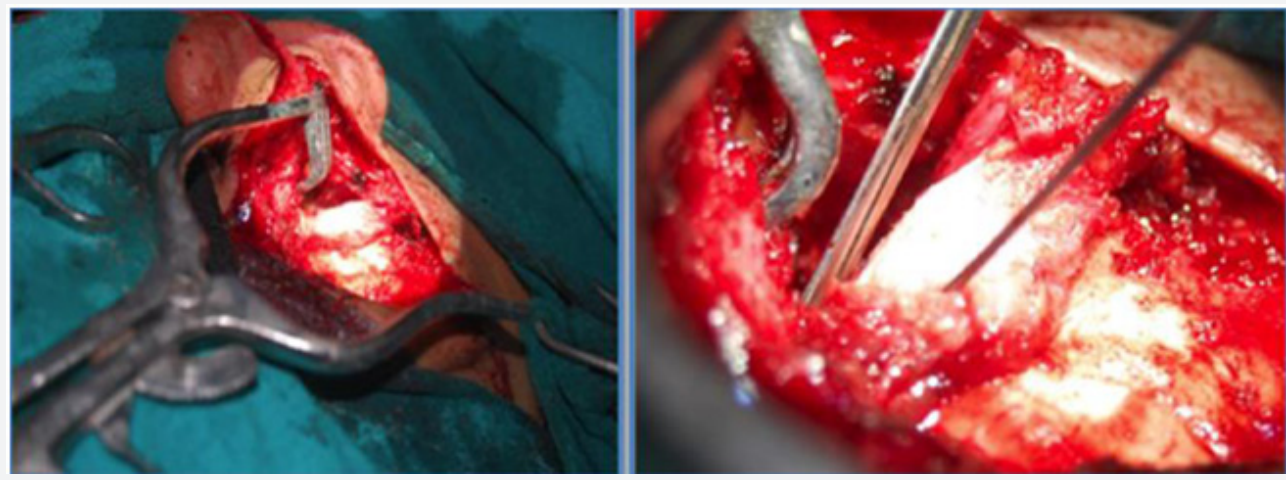

Figure 10: Repositioning of Musculofascioperiosteal flap over the masoid Cavity.

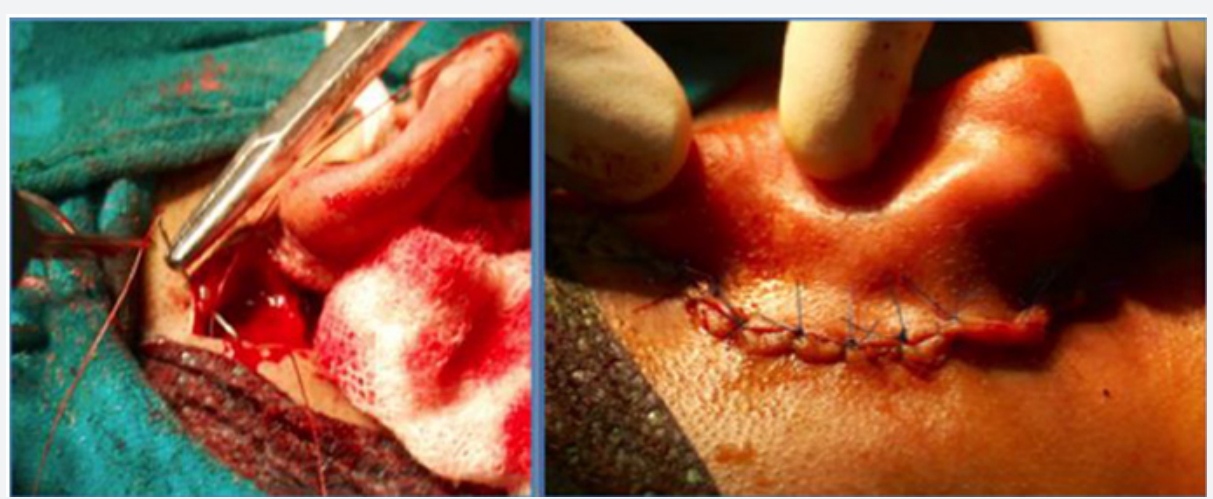

Figure 11: Skin Closer. 


\section{Global Journal of Otolaryngology}

The result of our study was analyzed in terms of:

Mean of healing time (dry ear) between group A and group B patients and, the data collected was statistically analyzed using Statistical Package for Social Sciences (SPSS) 23.0 software after consulting a biostatistician. Independent $\mathrm{T}$ test was applied.

\section{Results}

There were $8(53.3 \%)$ male patients and 7 (46.6\%) female patients in both obliterated and non-obliterated groups. There was no statistically significant difference noted in gender distribution in both the groups $(\mathrm{p}=1.00)$ (Table 1) and (Figure 11). The observation showed that maximum number of cases fall in the age group of 10-19 years with frequency of 6 (40\%) in non-obliterated group and $10(66.6 \%)$ in obliterated group, followed by 6 (40\%) non-obliterated and $3(20 \%)$ obliterated in age group of 20-29 years. The minimum frequencies 1 (6.6\%) were seen in age group of 40-49 years in both non-obliterated and obliterated group. There was no statistically significant difference noted in age distribution in both group ( $p=0.416)$ (Table 2) and (Figure 12). The average healing period in group A (MRM with obliteration) was 10.67 weeks and in group B (MRM without obliteration) was 12.47 weeks. There was statistically significance in healing time between the two groups ( $\mathrm{p}$ value $=0.005$ ) (Table 3) and (Figure 13). On comparing the healing time (weeks) between MRM with obliteration (Group A) and MRM without obliteration (Group B) with 15 cases in each group in which group A healed faster $10.67 \pm 1.447$ weeks than that of group B $12.47 \pm 1.807$ which was statistically significant p-value $=0.005$ (Table 4$)$ and (Figure 14).

Table 1: Gender Distribution of Patient in Two Groups.

\begin{tabular}{|c|c|c|c|}
\hline Groups & Male & Female & P-Valu \\
\hline $\begin{array}{c}\text { Group A (MRM With } \\
\text { Obliteration (n=15) }\end{array}$ & $8(53.3 \%)$ & $7(46.6 \%)$ & \\
\cline { 1 - 2 } $\begin{array}{c}\text { Group B (MRM With } \\
\text { Obliteration (n=15) }\end{array}$ & $8(53.3)$ & $7(46.6 \%)$ & 1 \\
\hline
\end{tabular}

Table 2: Age Distribution of the Patient in Two Groups.

\begin{tabular}{|c|c|c|c|}
\hline $\begin{array}{c}\text { Age } \\
\text { Groups } \\
\text { (Years) }\end{array}$ & $\begin{array}{c}\text { Group A (MRM } \\
\text { With Obliteration } \\
\text { (n=15) }\end{array}$ & $\begin{array}{c}\text { Group B (MRM } \\
\text { With Obliteration } \\
\text { (n=15) }\end{array}$ & \multirow{2}{*}{ P-Value } \\
\cline { 1 - 2 } $10-19$ & $10(66.6)$ & $6(40 \%)$ & \multirow{2}{*}{0.416} \\
\hline $20-29$ & $3(20 \%)$ & $6(40 \%)$ & \multirow{2}{*}{$0.40)$} \\
\hline $30-39$ & $1(6.6 \%)$ & $2(13.3 \%)$ & \\
\hline $40-49$ & $1(6.6 \%)$ & $1(6.6 \%)$ & \\
\hline
\end{tabular}

\section{Frequency (\%) of gender distribution among obliterated and non-obliterated group}

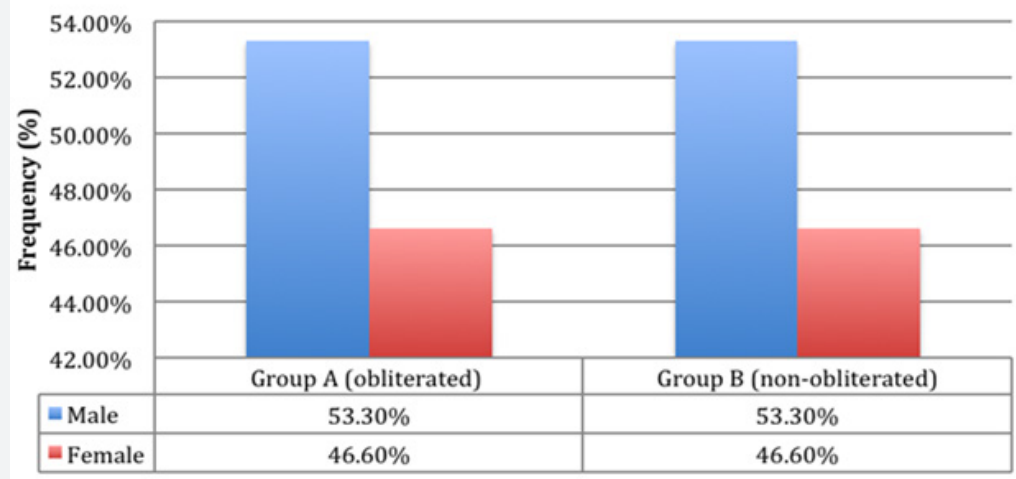

Figure 12: Bar diagram showing frequency (\%) of gender distribution among obliterated and non-obliterated groups

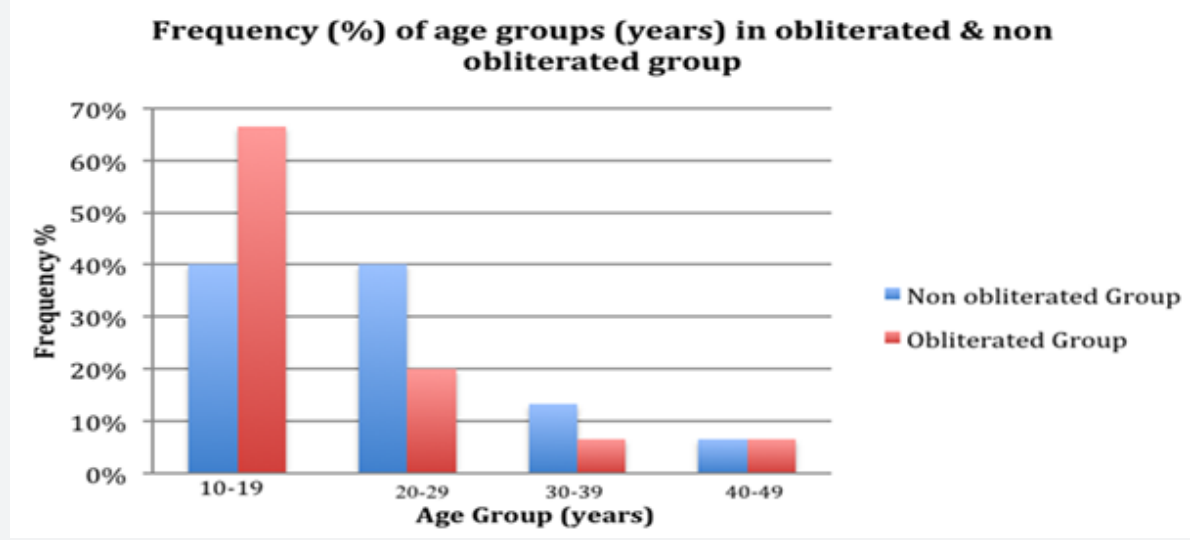

Figure 13: Bar diagram showing frequency (\%) of Age groups in obliterated and Non obliterated group 
Table 3: Healing Time (Average) Of Mastoid Cavity of Two Groups.

\begin{tabular}{|c|c|}
\hline Group & Average healing (Weeks) \\
\hline $\begin{array}{c}\text { Group A (MRM With Obliteration } \\
(\mathrm{n}=15)\end{array}$ & 10.67 \\
\hline $\begin{array}{c}\text { Group B (MRM With Obliteration } \\
(\mathrm{n}=15)\end{array}$ & 12.47 \\
\hline
\end{tabular}

Table 4: Comparison of Healing Time between Two Groups.

\begin{tabular}{|c|c|c|c|c|c|}
\hline \multirow{4}{*}{$\begin{array}{c}\text { Healing } \\
\text { Time } \\
\text { (Weeks) }\end{array}$} & $\begin{array}{c}\text { Type of } \\
\text { Surgery }\end{array}$ & N & $\begin{array}{c}\text { Mean+ Std. } \\
\text { Deviation }\end{array}$ & $\begin{array}{c}\text { Std. Error } \\
\text { Mean }\end{array}$ & P Valu \\
\cline { 2 - 6 } & Obliteration & 15 & $\begin{array}{c}10.67 \pm \\
1.447\end{array}$ & 0.374 & 0.005 \\
\cline { 2 - 6 } & $\begin{array}{c}\text { MRM Without } \\
\text { Obliteration }\end{array}$ & 15 & $\begin{array}{c}12.47 \pm \\
1.807\end{array}$ & 0.467 & \\
\hline
\end{tabular}

\section{Group A obliterated}

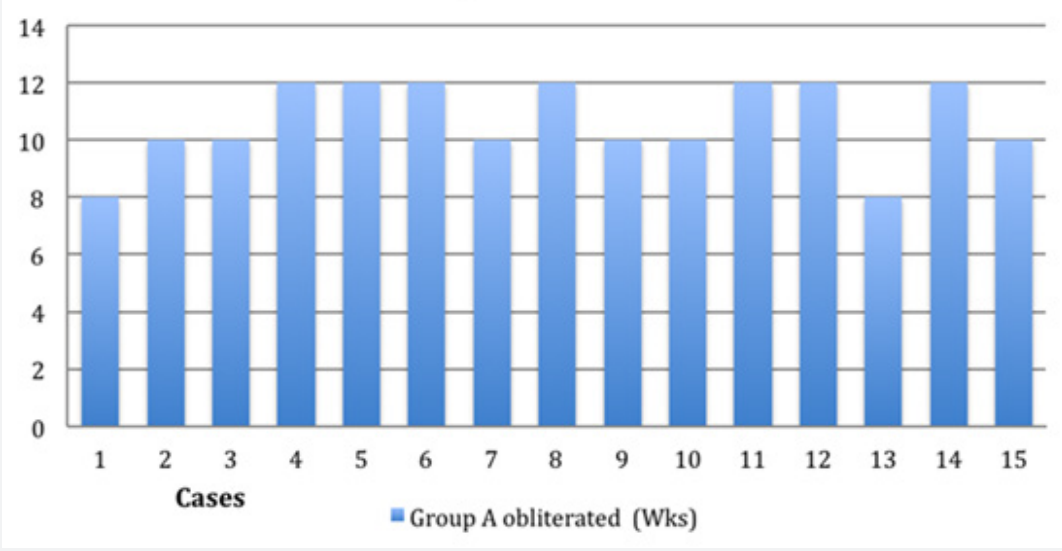

Figure 14: Bar Diagram Showing Healing Time of Mastoid Cavity In Group A (Mrm With Obliteration).

\section{Discussion}

The surgical management of COM squamosal active type is to eradicate the disease, have dry ear, prevent recurrence and to reconstruct the hearing mechanism. CWU an intact posterior meatal wall or closed procedure employs combined approach in which the posterior canal wall remains intact and keeps the EAC and mastoid cavity separate (closed). Though it gives dry ear, better hearing and less postoperative care, patients need long postoperative follow-up and chances of residual and recurrent cholesteatoma are high and may need for second or third look operation which is not feasible in underdeveloped country due to economic burden, lack of education and lack of proper transportation. CWD or open cavity mastoidectomy is one of the management options with the long-term goal of the surgery to provide the patient with a safe, dry and 'selfcleaning' ear, however, a significant number of patients (ranging from $20-60 \%$ ] [21]. Have a discharging mastoid cavity which is distressing and predisposes them to open cavity problems like persisting otorrhea, regular ear toileting, wax-debris formation and dizziness in cold weather and during swimming, wide meatoplasty, difficulties in placement of hearing aid device [22]. Thus, two-stage operation, and regular follow-up are a problem for them [23]. Considering the fact, we compared between the CWD with and without mastoid obliteration techniques so as to find out the healing time and open cavity problems.

In this study, we used inferiorlybased musculofascioperiosteal flap based on post auricular artery with a sample size of 30 .
Chhapola S, Matta in a comparative study "Mastoid Obliteration Versus Open Cavity" had a sample size of 40. Ghiasi S [24] in prospective longitudinal study "Mastoid cavity obliteration with combined palva flap and bone pate" had 48 sample size. Wadhwa [25] prospective, interventional study "periosteo-temporofascial flap for cavity obliteration - first Indian study" had sample size of 50 [20]. Mokbel and Khafagy [26] conducted a prospective case series with 100 adults in "Single flap with three pedicles, bone pate and split-thickness skin graft for immediate mastoid obliteration after canal wall down Mastoidectomy". Singh V [27] in a retrospective consecutive case review had a 51 sample size in "Obliteration of the persistently discharging mastoid cavity using the middle temporal artery flap". In a Retrospective review "Canal wall reconstruction tympanomastoidectomy with mastoid obliteration" by Gantz BJ [28] had 127 sample size. In Saunders [21] "Mastoid misery: quantifying the distress in a radical cavity" had a sample size of 28 patients.

In this study we randomly allotted patients to group A and group B. In-group A patients underwent MRM with mastoid cavity obliteration where as in group B patients underwent MRM only. In Chhapola S, Matta [24] comparative study "Mastoid Obliteration Versus Open Cavity" patients were randomly divided into two groups of 20 each in which one group underwent mastoid obliteration and other had open cavity. Similarly Harun [29] had total 63 patients in which 18 had open cavity and obliteration. In our study, age range was 10-49 years in both groups. The mean age of group A was $19 \pm 8.611$ years and $22.93 \pm 8.11$ years in group $B$. The most common age range 
being 10-19years. The male population outstripped the female population (male $=8$, female $=7$ in group $A$; male $=8$, female $=7$ in group B). Yung [30] included patients with a range of 5-80 years and a total of 30 obliterations were performed on children below 16 years and the commonly affected population was male (64 males and 32 females). Ramsey [31] included total of 59 patients with age ranged from 4 to 84 years, with a mean age of 39 years. There was an even distribution between male patients $(n=28)$ and female patients $(n=31)$. All patients underwent CWD mastoidectomy and mastoid obliteration (MO) for COM. All the cases in both the groups were healed. The average healing period in group A was $10.67 \pm 1.447$ weeks and $12.47 \pm 1.807$ weeks in group B. There is statistically significance in healing time between the two groups in our study ( $p$ value=0.005). In a study by Wadhwa [25], used periosteo-temporofascial flap to obliterate the mastoid cavity, sample size being 50 (25 patients underwent obliteration technique and 25 patients non obliteration technique) and the aim of the study being comparison of healing rate of the mastoid cavity between two groups, showed the rate of healing faster in obliteration group. The total number of the obliterated cases that healed was 21 out of $25(84 \%)$ and in the non obliteration group it was 15 out of 25 $(60 \%)$. The average time of healing in obliteration group was 8 weeks and in non-obliteration group it was 16 weeks. Chhapola S, Matta [24] in a comparative study of "Mastoid Obliteration Versus Open Cavity" had a sample size of 40; patients were randomly divided into two groups of 20 each. The group of 20 controls had an open mastoid cavity. Out of the 20 cases, patients were divided in four groups of 5 each. For each group the mastoid cavity was obliterated with cartilage, bone dust, hydroxyapetite and Singapore swing. Healing of the cavity as evidenced by epithelialisation, at the end of 6 months, was better in those ears where cavity was obliterated $(90 \%)$ as compared to those with open cavity (70\%). Cases obliterated with bone dust and Singapore swing had better and early epithelialisation (100\%) as compared to cartilage and hydroxyapetite (80\%).

In our study, the patients were assessed thrice post operatively. The patients' assessment was on 10-14 days, the second on 4-6 weeks and the third and final assessment on 12 weeks after discharge from the hospital. A time range of 4-6 weeks for second follow up and after 12 weeks for third follow up was kept for the patients inhabiting far away from Bhairahawa, which could not come exactly on the mentioned time frame. In addition, the mastoid cavities in patients who had undergone MRM with mastoid obliteration were examined. The cavity was considered healed if there was no discharge or debris in the cavity or any other signs of infection. As CWD surgery secures good surgical view, lesions could be removed completely; nonetheless, its shortcomings are cavity problems, difficulties in the fitting of hearing aids, etc. [32]. To reduce such shortcomings, attempts have been made by reconstruction of posterior canal wall and obliteration of mastoid cavity. In studies examined the quality of life after mastoid obliteration felt by patients, it has been reported that self-confidence was improved, embarrassment or inconvenience was felt less, and self-consciousness was lessened. In addition, mastoid obliteration prevents and minimized changes of resonance of external auditory canal after CWD surgery [33]. In this study we only address short-term healing rates, which may change with time. Most of the concern for mastoid obliteration is that of residual disease which may be buried underneath the fillers and so to detect residual cholesteatoma, a long term follow up of these patients is necessary [30]. So, the limitations of our study are being small sample size and short term follow up.

\section{Conclusion}

The healing time is earlier in MRM with cavity obliteration group compared to non obliterated group. The obliteration technique is able to lessen the burdens of the open cavity problems and can be followed in developing countries mainly where adequate follow up is not feasible.

\section{References}

1. Browning GG, Merchant SN, Kelly G, Swan IR, Canter R, et al. (2008) Chronic otitis media. Scott-Brown's Otorhinolaryngology, Head and Neck Surgery, 7 th ed. London:Edward Arnold publisher Ltd;; 3395-445

2. WHO (2004) library cataloguing in-Publication Data Chronic Suppurative otitis media: Burden of illness and management options. World Health Organization, Geneva, p.19.

3. Adhikari P, Sinha BK, Pokhrel NR, Kharel B, Aryal R (2007) Prevalence of chronic suppurative otitis media in school children of Kathmandu district. J Inst Med 29(3): 10-12.

4. WHO (2015) Deafness and hearing loss.

5. Maharjan M, Bhandari S, Singh I, Mishra SC (2006) Prevalence of otitis media in school going children in eastern Nepal. Kath Univ Med J 4(16): 479-482.

6. Mills RP (1997) Management of chronic suppurative otitis media. In Scott-Brown's Otolaryngology, Vol 3, 6th ed. London: Reed Educational and Professional Publishing Ltd; 3/10/1-11.

7. Adhikari P (2009) Pattern of ear diseases in rural school children: experiences of free health camps in Nepal. Int J Pediatr Otorhinolaryngol 73(9): 1278-1280.

8. Berman S (1995) Otitis media in developing countries. Pediatrics 96(1): 126-131.

9. Monasta L, Ronfani L, Marchetti F, Montico M, Vecchi Brumatti L, et al. (2012) Burden of disease caused by otitis media: systematic review and global estimates. Plos One 7(4): e36226.

10. Göçmen H, Kiliç R, Ozdek A, Kizilkaya Z, Safak MA, et al. (2003) Surgical treatment of cholesteatoma in children. Int J Pediatr Otorhinolaryngol 67(8): 867-872.

11. Vaidya S, Agarwal A, Pagare R, Sharma VK (2006) Evaluation of application of a cream in postoperative mastoid cavities. Indian journal of otology 12: 33-37.

12. Sheey JL (1983) Cholesteatoma surgery: canal wall down procedures. Ann Oto lRhinol Laryngoln 97(1): 30-35.

13. Kveton JF (2003) Open cavity mastoid operations. GlasscockShambough Surgery of the Ear ( $5^{\text {th }}$ edn), New Delhi, India, pp.499-415.

14. Guragain RP (2011) How I do it? Mastoid cavity obliteration in children. Nepalese journal of ENT Head and Neck Surgery 2(2). 
15. Mehta RP, Harris JP (2006) Mastoid obliteration. Otolaryngol Clin North Am 39(6): 1129-1142.

16. Roberson JB, Mason TP, Stidham KR (2003) Mastoid obliteration: autogenous cranial bone pate reconstruction. Otol Neurotol 24(2): 132-140.

17. Yung M, Bennett A (2013) Use of mastoid obliteration techniques in cholesteatoma. Curr Opin Otolaryngol Head Neck Surg 21(5): 455-460.

18. Linthicum FH (2002) The fate of mastoid obliteration tissue: a histopathological study. Laryngoscope 112(10): 1777-1781.

19. Palva T (1979) Mastoid obliteration. Acta Otolaryngol Suppl 360: 152154.

20. Wadhwa V, Anand TS, Kumar S, Kathuria G, Rana I (2003) PeriosteoTemporofascial flap for cavity obliteration - first Indian study. Indian J Otolaryngol Head Neck Surg 55(3): 170-174.

21. Males AG, Grey RF (1991) Mastoid misery: quantifying the distress in a radical cavity. Clin Otolaryngol Allied Sci 16(1): 12-14.

22. Mehta RP, Harris JP (2006) Mastoid obliteration. Otolaryngol Clin North Am 39(6): 1129-1142.

23. Beutner D, Helmstaedter V, Stumpf R, Beleites T, Zahnert T, et al. (2010) Impact of partial mastoid obliteration on caloric vestibular function in canal wall down mastoidectomy. Otology \& neurotology 31(9): 13991403.

24. Chhapola S, Matta I (2014) Mastoid obliteration versus open cavity: a comparative study. Indian J Otolaryngol Head Neck Surg 66: 207-213.

25. Ghiasi S (2015) Mastoid cavity obliteration with combined palva flapand bone pate. Iran J Otorhinolaryngol 27(78): 23-28.
26. Mokbel KM, Khafagy YW (2012) Single flap with three pedicles, bone pate and split-thickness skin graft for immediate mastoid obliteration after canal wall down mastoidectomy. Eur Arch Otorhinolaryngol 269(9): 2037-2041.

27. Singh V, Atlas M (2007) Obliteration of the persistently discharging mastoid cavity using the middle temporal artery flap. Otolaryngol Head Neck Surg 137(3): 433-438.

28. Gantz BJ, Wilkinson EP, Hansen MR (2005) Canal wall reconstruction tympanomastoidectomy with mastoid obliteration. Laryngoscope 115(10): 1734-1740.

29. Harun A, Clark J, Semenov YR, Francis HW (2015) The Role of Obliteration in the Achievement of a Dry Mastoid Bowl. Otology \& neurotology: official publication of the American Otological Society, American Neurotology Society and European Academy of Otology and Neurotology 36(9): 1510-1517.

30. Yung M, Smith P (2007) Mid-temporal pericranial and inferiorly based periosteal flaps in mastoid obliteration. Otolaryngol Head Neck Surg 137(6): 906-912

31. Ramsey MJ, Merchant SN, McKenna MJ (2004) Postauricular Periosteal-Pericranial Flap for Mastoid Obliteration and canal wall down tympanomastoidectomy. Otol Neurotol 25(6): 873-878.

32. Meuser W (1985) The exenterated mastoid: A problem of ear surgery. Am J Otol 6(4): 323-325.

33. Jang CH, Lee JS (1999) The effect on acoustic characteristics of surgical modification of the external ear. Korean J Otolaryngol 42(12): 15011504.

\section{Your next submission with Juniper Publishers will reach you the below assets}

- Quality Editorial service

- Swift Peer Review

- Reprints availability

- E-prints Service

- Manuscript Podcast for convenient understanding

- Global attainment for your research

- Manuscript accessibility in different formats ( Pdf, E-pub, Full Text, Audio)

- Unceasing customer service

Track the below URL for one-step submission https://juniperpublishers.com/online-submission.php 